\title{
THINK LOCALLY, ACT LOCALLY: SPILLOVERS, SPILLBACKS, AND EFFICIENT DECENTRALIZED POLICYMAKING
}

\author{
HIKARU OGAWA \\ DAVID E. WILDASIN \\ CESIFO WORKING PAPER NO. 2142 \\ CATEgory 1: Public FinAnCE \\ NOVEMBER 2007
An electronic version of the paper may be downloaded
- from the SSRN website:
- from the RePEc website:
www.SSRN.com
www.RePEc.org \\ - from the CESifo website: \\ www.CESifo-group.org/wp
}




\title{
THINK LOCALLY, ACT LOCALLY: SPILLOVERS, SPILLBACKS, AND EFFICIENT DECENTRALIZED POLICYMAKING
}

\begin{abstract}
In this paper, we analyze a class of models in which there are interjurisdictional spillovers among heterogeneous jurisdictions, as illustrated for instance by $\mathrm{CO}_{2}$ emissions that affect the global environment. Each jurisdiction's emissions depend upon the local stock of private capital. Capital is interjurisdictionally-mobile and may be taxed to help finance local public expenditures. We show that decentralized policymaking leads to efficient resource allocations in important cases, even in the complete absence of corrective interventions by higher-level governments or coordination of policy through Coasian bargaining. In particular, even when the preferences and production technologies differ among the agents, the decentralized system can still result in globally efficient allocation.
\end{abstract}

JEL Code: H23, H77, Q58.

\author{
Hikaru Ogawa \\ School of Economics \\ Nagoya University \\ Nagoya, Aichi 464-8601 \\ Japan \\ ogawa@soec.nagoya-u.ac.jp
}

\author{
David E. Wildasin \\ Martin School of Public Policy \\ University of Kentucky \\ 401 Patterson Office Tower \\ Lexington, KY 40506-0027 \\ USA \\ dew@davidwildasin.us
}

First version June, 2003

This version August, 2007

The first version of this paper was prepared while Ogawa was visiting the Martin School of Public Policy at the University of Kentucky, on leave from Nagoya University. Initial results were presented in the Martin School Spring, 2003, Public Economics Workshop. 


\section{Introduction}

Urbanization, industrialization, and other economic activities produce greenhouse gas emissions that affect the earth's atmosphere and thus may produce important external effects. These and similar externalities create a presumption that decentralized policymaking is likely to produce socially inefficient outcomes, as individual jurisdictions - nations or subnational governments - neglect the spillover benefits created by their policies. Although we do not doubt the validity of such concerns in general, the following analysis shows that there is more to the story. National and subnational governments do not exist in economic isolation from the rest of the world. In particular, as we will show, the linkages that arise from decentralized competition for capital investment or other productive resources alter the incentives facing decentralized policymakers. Even when externalities are truly global in nature, completely decentralized policymaking may lead to socially-efficient outcomes.

In stating the key theme and distinguishing feature of our analysis so directly, we do not wish to claim more than is justified. As will become clear, decentralized policymaking in the presence of interjurisdictional spillovers may indeed produce inefficient outcomes in certain circumstances. A number of remedies are available with which to manage positive or negative external effects, whether they stem from pollution or from other causes. These include Pigouvian taxes and subsidies (Pigou 1920), Coasian bargaining (Coase (1960), Stigler (1966)), the folk theorem of repeated interactions (Fudenberg and Maskin (1986)), and other incentive mechanisms, e.g. Clarke (1971), Groves and Ledyard (1977), and Varian (1994) among others. Under appropriate circumstances, each of these offers some hope that externality-based inefficiencies may be mitigated or avoided altogether.

At the same time, however, we realize the limitations of these prescriptions. In the context of global environmental problems, for instance, no global authority has the power to implement corrective taxes or subsidies. Countries are far from symmetric, both spatially and temporally, implying that the folk theorem cannot provide us much hope in reality. Coasian 
bargaining may not be completely hopeless, since nations can and do enter into treaties with one another, but treaty negotiation and enforcement processes are obviously cumbersome and far from costless. This is especially true when the externalities in question, such as those arising from the emissions of greenhouse gases, are truly global in nature. These externalities affect literally every nation and negotiations with very large numbers of countries are highly complex and costly. The impasse over the ratification and implementation of the "Kyoto protocol" illustrates this problem.

Recognizing that there may be no perfect solutions to externality problems, it is all the more important to understand thoroughly the underlying nature of external effects in particular cases and verify precisely how inefficiencies may arise. The present paper focuses on the problem of multijurisdictional externalities associated with industrialization, urbanization, and economic development. An important theme in the literature of fiscal competition, exemplified by a well-known paper by Oates and Schwab (1988), is that both fiscal and regulatory instruments influence the amount and location of such externality-producing activities. ${ }^{1}$ In some cases, depending on the range of available instruments and on informational and other constraints, competitive pressures may lead governments to control pollution or other externalities efficiently, with the important proviso that these effects do not spill over jurisdictional boundaries. When there are interjurisdictional spillovers, the literature consistently finds, as intuition would suggest, that decentralized policymaking produces socially inefficient outcomes.

In this paper, we analyze a class of models in which there are interjurisdictional spillovers among heterogeneous jurisdictions and in which it nevertheless is the case that decentral-

\footnotetext{
${ }^{1}$ The literature on competition is reviewed, e.g., by Wilson (1999), Zodrow (2003), Wildasin and Wilson (2004); see these papers for additional references. The interaction between decentralized regulation and fiscal policymaking, emphasized by Oates and Schwab, arises in a different context in the literature of "fiscal zoning." See Hamilton (1975) and, for a more comprehensive treatment with many additional references, Fischel (2001). Studies that examine fiscal competition and spillovers include Wellisch (1994), Glazer (1999), Kunce and Shogren (2002), and Cremer and Gahvari (2004). See Wilson (1997) for a review and further references.
} 
ized policymaking may lead to efficient resource allocations, even in the complete absence of corrective interventions by higher-level governments or coordination of policy through Coasian bargaining. We emphasize that decentralized policymaking can still result in globally efficient allocations even when the preferences and production technologies differ among jurisdictions and governments only have information, and only care, about local environmental impacts. Our analysis exploits an admittedly stylized but very standard model of tax competition as its fundamental analytical tool. Transboundary pollution provides a useful illustrative example of the interjurisdictional spillovers that are the focus of our analysis, but the application of our model is not restricted to environmental issues. As we discuss briefly in the conclusion, the results of our analysis can be applied to many kinds of spillover issues, such as positive externalities associated with the development of human capital.

\section{The Model}

We begin by describing the model in its simplest form, deferring discussion of various generalizations until later. The basic model follows the canonical tax competition model with mobile capital and capital-related externalities, pioneered by Oates and Schwab (1988), with which some readers may be familiar.

\subsection{Preferences, Technologies, and Endowments}

Preferences. In this model, there are $N$ jurisdictions, within each of which a single representative agent resides. This agent consumes a composite private good, denoted by $x_{i}$ for jurisdiction $i$, a local public good $g_{i}$, both of which are goods, and also suffers from environmental damage $e_{i}$, which is a bad. ${ }^{2}$ The utility of the household residing in jurisdiction $i$ is

\footnotetext{
${ }^{2}$ The variable $g_{i}$ may be interpreted as a vector, so that the model allows for an arbitrary number of local public goods.
} 
denoted $u_{i}\left(x_{i}, g_{i}, e_{i}\right)$, with $u_{i x}>0, u_{i g}>0$, and $u_{i e}<0$, where $u_{i x}$ represents the marginal utility of the private good and $u_{i g}$ and $u_{i e}$ are interpreted similarly. Furthermore, the sign restriction on $u_{i e}$ is inessential; if $u_{i e}>0$, then commodity $e$ is interpreted as a local environmental "good" rather than a bad. We discuss other possible examples later, but for now continue with the interpretation of $e_{i}$ as environmental damage, a bad. Note that preferences may differ across jurisdictions; we do not assume that preferences are homogeneous.

Production technologies. Perfectly competitive private firms produce the composite private good in each jurisdiction. The production process uses capital, with $k_{i}$ the amount of capital employed in locality $i$. There is at least one immobile input to the production process, such as labor, land, or other (privately owned) natural resources (forests, minerals, etc.) The amounts of all of these inputs are treated as fixed (in particular, we abstract from labor/leisure tradeoffs and treat the size of the local labor force as exogenously given), so that local production can be written simply as $f_{i}\left(k_{i}\right)$. We assume a well-behaved neoclassical production function exhibiting constant returns to scale in all inputs, so that there are no pure profits (or, equivalently, pure profits are the return to one of the immobile factors of production), with $f_{i}$ increasing and strictly concave in the amount of capital; letting subscripts denote partial derivatives, this means that $f_{i k}>0>f_{i k k}$. Note that production functions may differ across jurisdictions; we do not assume that technologies are identical.

Public goods and environmental spillovers. The public good $g_{i}$ in each jurisdiction is produced using the all-purpose private good; each unit of $g_{i}$ requires one unit of this good. Public goods do not play a crucial role in the analysis and are included for the sake of generality and for comparison with environmental or other externalities.

Externalities do of course play a crucial role in the analysis. Environmental damage is linked to the use of the capital input: each unit of capital employed in jurisdiction $i$ results in $e$ in $a$ units of environmental damage there. In addition, the use of capital in jurisdiction $i$ causes environmental damage in other jurisdictions, that is, there are environmental spillovers. The 
degree of spillover is captured by a parameter $\beta$, with $\beta \in[0,1]$, so that

$$
e_{i}=a k_{i}+\beta \sum_{j \neq i} a k_{j}
$$

When $\beta=0$, environmental quality in any one jurisdiction depends only on local economic activity. In this case, our model reduces to that of Oates and Schwab (1988). If $\beta$ is positive, local economic activity (as represented by the level of capital, $k_{i}$ ) causes damage not only to the local environment but in other jurisdictions as well; a low value of $\beta$ means that these environmental spillovers are small. The upper limit of $\beta=1$ corresponds to complete or perfect spillovers, where a unit of capital employed in jurisdiction $i$ does just as much damage elsewhere as it does locally. By allowing for interjurisdictional spillovers, our model generalizes that of Oates and Schwab (1988) and others who have used similar models. Note that we do assume that the degree of environmental spillover is the same for all jurisdictions; the implications of relaxing this assumption are discussed later. Phenomena such as greenhouse gas emissions correspond to the case $\beta=1$ : a ton of $\mathrm{CO}_{2}$ emissions circulates and mixes uniformly throughout the atmosphere, no matter what its source.

Endowments. Let $\bar{k}_{i}$ denote the the amount of this stock with which jurisdiction $i$ is endowed. We assume that capital is freely mobile among jurisdictions and fixed in supply to the aggregate of all jurisdictions, so that

$$
\sum_{i} \bar{k}_{i}=\sum_{i} k_{i}
$$

This means that any one jurisdiction may import $\left(k_{i}>\bar{k}_{k}\right)$ or export $\left(\bar{k}_{i}>k_{i}\right)$ capital. Note that endowments may differ across jurisdictions; we do not assume that endowments are identical.

Note for future reference that (1) and (2) imply that

$$
e_{i}=a k_{i}+a \beta\left(\bar{k}-k_{i}\right)
$$

where $\bar{k} \equiv \sum_{i} \bar{k}_{i}$ is the aggregate capital stock. 


\subsection{Institutions}

The government in each jurisdiction controls public policy instruments - taxes and expenditures. Other resource allocation decisions are made by private-sector agents operating in competitive markets.

The composite private good that is produced and consumed in each jurisdiction is assumed to be tradable and is chosen as numeraire. Thus, the total value of production in locality $i$ is $f_{i}\left(k_{i}\right)$. The gross return per unit of capital is thus $f_{i k}\left(k_{i}\right)$, and the total return to the immobile factors of production, owned by the local resident, is $f_{i}\left(k_{i}\right)-k_{i} f_{i k}\left(k_{i}\right)$. In addition, households receive income from their endowments of capital and also pay a lump-sum tax $T_{i}$ to the local government. Denoting the net return to capital by $\rho$, the private good consumption of the household in jurisdiction $i$ is thus

$$
x_{i}=f_{i}\left(k_{i}\right)-f_{i k} k_{i}+\rho \bar{k}_{i}-T_{i} .
$$

In addition to a local lump-sum tax, the government in each jurisdiction has at its disposal a (source) tax on mobile capital. As a matter of notational convenience, the tax on capital $t_{i}$ is interpreted as a per-unit tax, although it could equivalently be modeled as an ad valorem tax on the value of capital such as a property tax or as a source-based tax on capital income, such as a corporation income tax. ${ }^{3}$ The government budget constraint requires that tax revenues are equal to government expenditures on the local public good,

$$
g_{i}=T_{i}+t_{i} k_{i}
$$

Capital mobility means that the net rate of return must be the same in every jurisdiction in equilibrium, i.e.,

$$
f_{i k}-t_{i}=\rho \quad \forall i
$$

\footnotetext{
${ }^{3}$ Although the precise specification of the form of taxation is sometimes important in the analysis of strategic tax competition, this is not the case in the present context since we assume that each jurisdiction is small relative to the capital market and we may thus specify a per-unit tax without loss of generality.
} 
This system of equations, together with the capital-market clearing condition (2), determines the equilibrium allocation of capital and the equilibrium net rate of return $\rho$ as functions of the vector of capital tax rates $t \equiv\left(t_{1}, \ldots, t_{n}\right)$.

\subsection{Decentralized Policy Equilibrium}

We assume that governments choose their policies to maximize the equilibrium level of utility of their residents. Each government is assumed to be small in the sense that it treats the economy-wide net return to capital $\rho$ and the policy choices of other governments as exogenously given. This means that the government in jurisdiction $i$ expects that its choice of the capital tax rate $t_{i}$ will affect the local capital stock $k_{i}$ because the local gross rate of return on capital $f_{i k}$ must be sufficiently high to insure that $f_{i k}-t_{i}=\rho$. This equation can be solved implicitly for $k_{i}\left(t_{i}\right)$, with $d k_{i} / d t_{i}=1 / f_{i k k}<0$.

Although the individual jurisdictions are assumed to act atomistically in choosing their policies, this does not mean that they ignore the effects of their policy choices on externality spillovers. When jurisdiction $i$ changes its tax rate on capital, it knows that there will be less environmental damage from local economic activity because $k_{i}$ will fall. However, the capital that leaves one locality does not disappear altogether from the economy, it merely relocates to other jurisdictions. Indeed, substituting $k_{i}\left(t_{i}\right)$ into $(3)$, one obtains

$$
\frac{d e_{i}}{d t_{i}}=(1-\beta) a \frac{d k_{i}}{d t_{i}} .
$$

In other words, each jurisdiction, though acting atomistically, and without knowledge of the precise general equilibrium reallocation of capital that results from its own tax policy, nevertheless recognizes that inflows or outflows of capital do not correspond to the creation or destruction of capital itself.

Using the government budget constraint (5) to solve for $T_{i}$ and substituting into (4), we get

$$
x_{i}=f_{i}\left(k_{i}\right)-k_{i} f_{i k}\left(k_{i}\right)+\rho \bar{k}_{i}-g_{i}+t_{i} k_{i} .
$$


Having thus eliminated $T_{i}$ from the system, the problem facing the government in jurisdiction $i$ is to choose two policy instruments, $g_{i}$ and $t_{i}$, to maximize $u\left(x_{i}, e_{i}, g_{i}\right)$, taking $\rho$ as given and taking into account the effect of the local capital tax on the equilibrium value of the local capital stock and thus on local environmental quality (via (3)) and on local private good consumption (via (8)).

The two first-order conditions that describe the solution to this local optimization problem are

$$
\begin{gathered}
\frac{u_{i g}}{u_{i x}}=1 \\
t_{i}=-a(1-\beta) \frac{u_{i e}}{u_{i x}} .
\end{gathered}
$$

The first of these conditions is the Samuelson condition for efficient local public expenditures; since local governments can raise as much revenue as desired through lump-sum taxation, the Samuelson condition is naturally expected to be satisfied. The second condition shows how governments tax mobile capital. This tax is imposed at a positive rate if local residents value environmental quality, since then $u_{i e}<0$ (strictly). However, governments also take into account the fact that some proportion $\beta$ of the local environmental damage that is avoided by driving capital out of their own jurisdictions will "spill back" when capital relocates elsewhere. ${ }^{4}$

\subsection{Efficient Resource Allocation}

In order to evaluate the efficiency properties of the decentralized policy-setting equilibrium just described it is necessary to characterize a Pareto-efficient allocation of resources, that is, a solution to the problem

$$
\max _{<\left(x_{i}, g_{i}, k_{i}\right)>} u_{1}\left(x_{1}, g_{1}, e_{1}\right)
$$

\footnotetext{
${ }^{4}$ To assume that governments take "spill back" effects into account does not require that they monitor the sources of these effects, which are irrelevant. Furthermore, taking these effects into account is not a departure from the assumption of atomistically competitive competition among governments. Spillovers, and thus spillbacks, arise from the fundamental technology of pollution, as specified in (3).
} 
subject to

$$
\begin{gathered}
u_{i}\left(x_{i}, g_{i}, e_{i}\right)-\bar{u}_{i}=0 \quad \forall i>1, \\
\sum_{i} f_{i}\left(k_{i}\right)-\sum_{i}\left(x_{i}+g_{i}\right)=0,
\end{gathered}
$$

(1), and (2).

The first-order conditions characterizing the solution to this problem yield (after some slight manipulation)

$$
\begin{gathered}
\frac{u_{i g}}{u_{i x}}=1 \\
f_{i k}+a \frac{u_{i e}}{u_{i x}}+\beta \sum_{\ell \neq i} a \frac{u_{\ell e}}{u_{\ell x}}=f_{j k}+a \frac{u_{j e}}{u_{j x}}+\beta \sum_{\ell \neq j} a \frac{u_{\ell e}}{u_{\ell x}} \quad \forall i, j .
\end{gathered}
$$

The first of these is again the Samuelson condition for efficient local public expenditure. The second condition characterizes the efficient allocation of capital, taking into account both the productivity of capital and the impact of the capital allocation on local environmental damage and on spillovers. At the margin, a unit of capital must be equally productive in all locations, net of the environmental damage that is causes in its own location and, through spillover effects, in other locations.

\subsection{The Efficiency of Decentralized Policymaking}

It is immediately apparent that the equilibrium conditions (6), (9), and (10) correspond to the efficiency conditions (13) and (14) when there are no spillovers, i.e., when $\beta=0$. In this case, each government's local capital tax provides an instrument with which to control the extent of local environmental damage, while the lump-sum tax provides an efficient source of local finance for public expenditures. Thus, our analysis confirms the findings of Oates and Schwab (1988) for the case where our model reduces to theirs, that is, when there are no interjurisdictional spillover effects. 
Remarkably, the same result holds even when there are spillover effects:

Proposition 1: The equilibrium allocation of resources in a system with decentralized policymaking is first-best Pareto efficient.

Proof: Adding and subtracting $\beta u_{i e} / u_{i x}$ to the left-hand side of the efficiency condition (14), and similarly adding and subtracting $\beta u_{j e} / u_{j x}$ on the right-hand side, it is clear that (14) is satisfied if and only if

$$
\begin{array}{r}
\left(f_{i k}+a(1-\beta) \frac{u_{i e}}{u_{i x}}+\beta \sum_{\ell} a \frac{u_{\ell e}}{u_{\ell x}}\right)-\left(f_{j k}+a(1-\beta) \frac{u_{j e}}{u_{j x}}+\beta \sum_{\ell} a \frac{u_{\ell e}}{u_{\ell x}}\right)= \\
\left(f_{i k}+a(1-\beta) \frac{u_{i e}}{u_{i x}}\right)-\left(f_{j k}+a(1-\beta) \frac{u_{j e}}{u_{j x}}\right)=0 \quad \forall i, j .
\end{array}
$$

But (6) and (10) imply that this condition is indeed satisfied in equilibrium; furthermore, the Samuelson condition (13) for efficient public good provision is also satisfied in equilibrium, as shown in $(9) .^{5}$

Thus, even though each local government (i) chooses policies that represent the interests only of their local resident(s), (ii) is unaware of the amount of damage that local economic activity causes in other jurisdictions (recall that there are no symmetry assumptions regarding preferences, technologies, or endowments, and thus no local government $i$ knows the valuation $u_{j e} / u_{j x}$ placed on environmental damage in any other jurisdiction $j \neq i$ ), and (iii) does not communicate, bargain, or coordinate policies with other local governments, the process of decentralized policymaking produces Pareto-efficient outcomes for the entire system of jurisdictions. To achieve efficient resource allocation in this economy with environmental spillovers, it is necessary neither to have a benevolent Pigovian "visible" hand, for example in the form of a higher-level government that imposes corrective taxes on spillovers,

\footnotetext{
${ }^{5}$ To be precise, the correspondence of first-order conditions does not establish that decentralized equilibria are efficient; this is necessary but not sufficient. In this simple model, however, standard assumptions on preferences and technologies guarantee that the necessary conditions are also sufficient.
} 
nor to have a somewhat "less visible" hand, for example in the form of a system of treaties or contractually-fixed compensatory payments resulting from a Coasian negotiation, that internalize damages resulting from spillovers. This is true whether the spillover effects, as measured by the parameter $\beta$, are small or large, and possibly even "global," corresponding to the case where $\beta=1$.

Indeed, since the analysis places no restrictions even on the sign of the local valuation of environmental damage $u_{i e} / u_{i x}$, it is possible that there are "asymmetric" externalities in the sense that residents in some jurisdictions may be indifferent to environmental quality $\left(u_{i e} / u_{i x}=0\right)$, others regard environmental damage as very harmful $\left(u_{i e} / u_{i x}<<0\right)$, and still others view it (for some odd reason) as positively desirable $\left(u_{i e} / u_{i x}>>0\right)$. (Indeed, Stern (2007, Section 3.3) notes that modest global warming may produce some benefits in northern regions even as it harms other regions.)

Qualifications. Proposition 1 is derived within the context of a model that is very general in some respects, but of course it does depend on other assumptions that are less general. For example, one could imagine that the amount of environmental damage produced per unit of investment in a given jurisdiction might differ: instead of some fixed amount of damage $a$ that is the same for all jurisdictions, there might be climatic, topographical, or regulatory variations among jurisdictions such that the amount of damage caused by each unit of capital in jurisdiction $i$ is an amount $a_{i}$, not necessarily the same in all places. Furthermore, the amount of "physical" spillover from one jurisdiction to another might not be the same proportion $\beta$ for all jurisdictions; instead, there could be a parameter $\beta_{i j}$ that describes the amount of pollution transmitted (by air, water, etc.) from jurisdiction $i$ to jurisdiction $j$ which could vary across all $i$ and $j$. In these cases, the proof of Proposition 1 is no longer valid.

Furthermore, the externalities that we have analyzed are not the only conceivable form of externalities. For example, jurisdictions might derive spillover externalities from public 
expenditures undertaken by others; in one simple polar case. One might assume, for instance, that the utility in jurisdiction $i$ depends not on $g_{i}$ alone but on the total amount of public spending in all jurisdictions $\sum_{j} g_{j}$, in effect producing a "voluntary contributions" model of local public good provision (see, e.g., Boadway et al. (1989)).

Nevertheless, Proposition 1 is still a striking result, and it should be apparent that the magnitude of the efficiency losses from decentralized policymaking is modest if the assumptions of the model are approximately correct. For example, suppose that we generalize the model to let $\beta_{i j}$ represent the amount of environmental damage suffered in $j$ per unit of damage in $i$. The Samuelson condition for efficient public expenditure continues to be satisfied in the decentralized equilibrium while the equilibrium allocation of capital will no longer be efficient: $k_{i}$ will be inefficiently high in some jurisdictions and inefficiently low in others. The equilibrium allocation of capital in the model would be continuous in the parameters $\beta_{i j}$, however, converging to the efficient allocation as the spillover parameters approach a common value $\left(\beta_{i j} \rightarrow \beta\right)$. The key point is that spillovers themselves do not imply any necessary departure from efficiency in decentralized policymaking, even when there are potentially very substantial asymmetries among the preferences, technologies, and endowments of different jurisdictions. The efficiency rationale for intervention in local decisionmaking by a higherlevel authority, or for explicit coordination and bargaining among local governments, must rest not on the "first-order" existence of spillovers but on the "second-order" differences in the amounts of spillover damage from one jurisdiction to another (i.e., not on the fact that $\beta_{i j}>0$ but on the fact that $\beta_{i j} \neq \beta_{k l}$ for some $\left.i, j, k . l\right)$. 


\section{$3 \quad$ Extensions and Interpretations}

\subsection{Many Mobile Resources}

The model in Section 2 assumes that "capital" is the only resource that is mobile among jurisdictions. Here, we extend the model to allow for $M$ distinct types of mobile resources. This is not merely a formal generalization. The second part of this section discusses interpretations and applications of the analysis for which this generalization is crucial. To anticipate some of these interpretations, one might suppose that nonhuman capital is mobile among regions but that human capital, or labor of different types, is also mobile, and that there are some externalities, positive or negative, associated with different types of labor. ${ }^{6}$

The basic setup and notation of the previous section can be preserved here. We change the model only by interpreting $k_{i}, \bar{k}_{i}$, etc. as vectors; thus, $k_{i}=\left(k_{i}^{1}, \ldots, k_{i}^{m}, \ldots, k_{i}^{M}\right)$, and similarly for other $M$-vectors. We assume that each government can impose taxes (or subsidies) at different rates, as desired, on mobile resources. Thus, $t_{i}$ is also a vector of dimension $M$. Each type of mobile resource may give rise to a different type of externality, with $e_{i}^{m}$ the externality associated with the mobile resource of type $m$ in jurisdiction $i$; the parameters $a^{m}$ and $\beta^{m}$ are specific to each type of mobile resource, which means that some of them may not give rise to any spillover effects at all $\left(\beta^{m}=0\right)$ while others do $\left(\beta^{m}>0\right)$. Thus, (1) is now interpreted to mean that the $m$-th component of the vector $e_{i}$ is given by $e_{i}^{m}=a^{m} k_{i}^{m}+\beta^{m} \sum_{j \neq i} k_{j}^{m}$. The vector $e_{i}$ enters the utility function $u_{i}\left(x_{i}, g_{i}, e_{i}\right)$ in a general way; in particular, some "externalities" may be zero $\left(u_{i e}^{m}=0\right.$, where the superscript identifies the $m$-th mobile resource) while others may be positive or negative, and the sign and magnitudes of these effects may differ among jurisdictions. In the special case where different types of mobile resources produce the same kinds of external effects, the external

\footnotetext{
${ }^{6}$ To forestall possible confusion, let us note that it is still important for the analysis that the "representative agent" in each jurisdiction is immobile and that local policies are chosen to maximize the utility of this agent, so we do not necessarily suggest that the model accommodates the case where all people are mobile. See further discussion in the next subsection.
} 
effects enter the utility function as perfect substitutes (thus, for example, different types of resources may result in noise pollution, and the decibels of noise associated with each type are simply added up to determine the total amount of noise that affects consumer welfare).

As in Section 2, the total stock of each mobile resource in the economy as a whole is taken as exogenously fixed. The vector of equilibrium net rates of return for these resources is denoted by $\rho$. As before, the equilibrium amount of each mobile resource located in jurisdiction $i$ must satisfy (6), which is now a system of $M$ equations that, together with the $M$ equations (2), determine the equilibrium values of the $M+N M$ variables $\left(\rho, k_{1}, \ldots, k_{N}\right)$.

The government and household budget constraints take the same forms as before, and each jurisdiction chooses its tax and public expenditure policies taking as given the net rate of return on mobile resources, but recognizing that its tax policies affect the incentive for mobile resource owners to locate within its boundaries. The impact of local taxes on the allocation of mobile resources is now somewhat more complex than before because the entire vector of mobile resources enters the production function $f_{i}\left(k_{i}\right)$ with no restrictions as to substitutability/complementarity among these inputs. Thus, a change in jurisdiction $i$ 's tax rate on mobile resource $m, t_{i}^{m}$ will, in general, affect the entire vector $k_{i}$. Let $F_{i K K}$ denote the matrix $\left[\partial^{2} f_{i} / \partial k_{i}^{m} \partial k^{m^{\prime}}\right]$. This matrix is negative definite because $f_{i}\left(k_{i}\right)$ is strictly concave. Using the implicit function theorem to solve the system (6) for the vector $k_{i}\left(t_{i}\right)$, treating $\rho$ as given, one obtains

$$
\frac{\partial k_{i}^{m}}{\partial t_{i}^{m^{\prime}}}=\frac{\left|F_{i K K}^{m m^{\prime}}\right|}{\left|F_{i K K}\right|}
$$

where $F_{i K K}^{m m^{\prime}}$ denotes the cofactor of the $\left(m, m^{\prime}\right)$ element in $F_{i K K}$. It follows from the concavity of $f_{i}$ that $\partial k_{i}^{m} / \partial t_{i}^{m}<0$, but the cross-effects of taxes on employment of mobile inputs $\partial k_{i}^{m} / \partial t_{i}^{m^{\prime}}$, for $m \neq m^{\prime}$, may in general be of either sign, or zero.

To characterize jurisdiction $i$ 's choice of its tax structure, note from (8) that 


$$
\frac{d x_{i}}{d t_{i}^{m}}=t_{i} \frac{\partial k_{i}}{\partial t_{i}^{m}}
$$

while, from (3),

$$
\frac{d e_{i}}{d t_{i}^{m}}=a(1-\beta) \frac{\partial k_{i}}{\partial t_{i}^{m}}
$$

where $a(1-\beta)$ is the vector $\left(a^{m}\left(1-\beta^{m}\right)\right)$. Letting $u_{i e}$ now represent the vector $\left(u_{i e}^{m}\right)$, it follows that the solution to government $i$ 's problem of choosing a vector of tax rates $t_{i}$ and public expenditures $g_{i}$ to maximize utility for the representative resident of jurisdiction $i$ is characterized by the first-order conditions

$$
\begin{gathered}
\frac{u_{i g}}{u_{i x}}=1 \\
t_{i} \frac{\partial k_{i}}{\partial t_{i}^{m}}=-\frac{u_{i e}}{u_{i x}} a(1-\beta) \frac{\partial k_{i}}{\partial t_{i}^{m}}, \quad m=1, \ldots, M .
\end{gathered}
$$

Condition (18) is just the Samuelson condition for local public expenditures once again, while (19) is a system of $M$ equations that simultaneously characterize the locality's choice of the tax rate vector $t_{i}$. This condition is obviously satisfied if

$$
t_{i}^{m}=-a^{m} \beta^{m} \frac{u_{i e}^{m}}{u_{i x}} \quad \forall m
$$

and indeed (20) must necessarily hold at a solution to jurisdiction $i$ 's optimization problem since the $M \times M$ matrix $\left[\partial k_{i} / \partial t_{i}\right]$ must be of full rank. ${ }^{7}$ Thus, Section 2's characterization of a locality's choice of the tax rate on mobile resources, (10), can be interpreted as a characterization of the vector of tax rates applied to each of many different mobile resources.

The characterization of the efficient allocation of resources is essentially no different in the case where there are many mobile resources rather than just one. Once again, the Samuelson condition for efficient local public expenditures must hold, while the condition for efficient capital allocation (14) must hold for each of the mobile resources, i.e.,

$$
f_{i k}^{m}+a^{m} \frac{u_{i e}^{m}}{u_{i x}}+\beta^{m} \sum_{\ell \neq i} a^{m} \frac{u_{\ell e}^{m}}{u_{\ell x}}=f_{j k}^{m}+a^{m} \frac{u_{j e}^{m}}{u_{j x}}+\beta^{m} \sum_{\ell \neq j} a^{m} \frac{u_{\ell e}^{m}}{u_{\ell x}} \quad \forall i, j \text { and } \forall m .
$$

\footnotetext{
${ }^{7}$ This follows from the strict concavity of the production function $f_{i}$.
} 
Using exactly the same method of proof, it is now apparent that Proposition 1 can be extended to the case of $M$ mobile resources.

\subsection{Productivity Spillovers}

It is sometimes argued that FDI promotes productivity growth through positive production externalities, for instance, because multinational enterprises may possess superior production technology and management techniques [Blomstrom and Kokko (1998)]. On the other hand, production externalities may arise, possibly in attenuated from, from knowledge or other spillovers that do not depend on the co-location of production activities. As an extension of the earlier analysis, let us consider alternative model in which capital investment produces positive spillovers. Although it certainly does not represent all conceivable types of production externalities, this extension does clearly show that production externalities do not necessarily result in inefficient outcomes; in particular, the key findings in Section 2 continue to hold.

We continue to use the basic setup and notation of Section 2. Assume that the production function is now given by $f_{i}\left(K_{i}\right)$, where $K_{i} \equiv k_{i}+\alpha \sum_{j \neq i} k_{j}$, thus incorporating an interjurisdictional production externality parameterized by $\alpha$. (Intrajurisdictional spillovers are subsumed within the local production function.) As $\alpha \rightarrow 0$, the spillover effect becomes weaker and ultimately vanishes. In the presence of such spillover effects, inefficiencies might arise because individual governments would not take into account the fact that their policies influence productivity in other locations.

The equilibrium conditions (6) and (2) still hold in this model. Taking total derivatives of these equations, the effect of changes in jurisdiction $i$ 's capital tax on its capital stock is

$$
\frac{\partial k_{i}}{\partial t_{i}}=\frac{1}{f_{k k}^{i}(1-\alpha)}<0,
$$


As in Section 2, governments maximize $u_{i}\left(x_{i}, g_{i}\right)$. The first-order conditions for the local optimization problem are

$$
\begin{gathered}
\frac{u_{i g}}{u_{i x}}=1 \\
t_{i}=\alpha f_{i k}>0 .
\end{gathered}
$$

The second condition reflects the fact that government $i$ has an incentive to tax local investment. Substituting (24) into (6), we have

$$
f_{i k}=\rho(1-\alpha)^{-1} \quad \forall i
$$

Pareto efficient allocation of mobile capital requires that

$$
f_{i k}(1-\alpha)=\mu / \lambda \quad \forall i
$$

where $\mu$ and $\lambda$ are Lagrange multipliers. The equilibrium conditions with decentralized policymaking imply that this condition is satisfied, and that the decentralized equilibrium is therefore efficient.

\subsection{Applications and Interpretations}

We now discuss several different contexts in which the preceding results can be applied.

"Good" and "Bad" Industries. Many governments attempt to devise packages of fiscal (and other) incentives to attract or retain "desirable" firms or industries. For example, a "desirable" industry could be one whose activities produce little pollution (a "clean" industry), and an "undesirable" industry could be one that pollutes heavily. In both of these cases, spillover effects (or the lack thereof) can be an important characteristic of an industry's environmental impact. Some regions or countries (e.g., rich regions or first-world countries) may place a higher premium on environmental quality than others (e.g., poor regions or third-world countries), for example because environmental quality is a normal good, leading 
them to tax dirty industries more heavily and causing some relocation of dirty industries to other regions, a phenomenon sometimes described pejoratively as "ecological dumping." Since environmental damage may spill across jurisdictional boundaries, however, the ability of any one jurisdiction to improve its environmental quality at the expense of others may be limited. (In the extreme cases of global environmental phenomena such as global warming (attributable to greenhouse gas emissions) and ozone depletion (attributable to CFC emissions), there is no way for any one jurisdiction to shift the burden of environmental damage to some other location.) But by the same token, the apparent potential for "market failure" seems to increase in such cases since individual jurisdictions (presumably) ignore the spillover effects that result from changes in the amount of pollution occurring within their boundaries. Our analysis shows that decentralized competition for "clean" and "dirty" industries can result in an efficient spatial allocation of these activities even when individual jurisdictions pay no attention at all to the impact of their decisions on the welfare of those in other locations.

As previously remarked, the formal analysis presented above does not require that mobile resources produce negative externalities; it is equally applicable in the case of positive externalities. It is sometimes claimed that some industries produce positive local spillovers because they attract and employ highly educated staff (scientists, medical personnel, economists (?)) whose presence in a region benefit other residents. The range of such potential spillovers (which are in any case not easily quantified) is very large and could include the potential for the development of new firms, positive peer-group effects on local educational systems, lower crime rates, greater local product variety, etc. Not all of these potential spillovers can be captured perfectly in our model, but their essential characteristic is that the presence of these particular types of people benefit existing residents of a jurisdiction - while, at the same time, some of the local benefits may spill over to other jurisdictions. Interpreting one of the mobile resources in the model of the previous subsection to be, say, "highly educated workers," while other mobile resources represent various forms of non-human capital, one 
can see that decentralized competition for these desirable workers, or the firms or industries that employ them, can result in a spatial allocation of externality-producing activities that is efficient from the viewpoint of the system as a whole.

Pollution Permits. In some cases, the total amount of pollution may be very closely linked to the total stock of non-human capital, as in the Oates-Schwab tradition. More generally, however, it might be possible vary the amount of pollution associated with a given level of investment or production. In that case, additional policy instruments may be needed to achieve an efficient allocation of resources.

The use of tradable pollution permits as a means to control pollution has long attracted the interest of economists and such permits are now used in the US and in the EU. As these policies are usually conceived, an agency of a higher-level government, such as the Environmental Protection Agency in the US, might set an overall target level of (say) $\mathrm{SO}_{2}$ emissions for the country as a whole, some overall target for $N O_{x}$ emissions, etc., and then proceed to issue permits for these target amounts of pollution. This is already a challenging task for the national government, but it is even more difficult to determine the efficient distribution of emissions among the 50 states and among thousands of local jurisdictions. And yet the spatial distribution of emissions is very important because environmental damages are not uniform throughout the nation. Equipped with information about local preferences for pollution, and taking into account the interjurisdictional spillovers that are associated with pollution emissions in any one location, the EPA could in principle find the efficient amount of emissions for each locality in the US and then auction just that amount of permits in each locality. In the absence of such information, trade in permits could conceivably produce an equilibrium in which pollution is concentrated in localities where damages are high, a highly inefficient outcome.

Suppose, however, that localities are able to tax (or subsidize) the purchase of permits by local firms in ways that reflect local preferences for environmental quality. By suitable rein- 
terpretation, the model presented above can be used to analyze the equilibrium of a system in which a national authority determines an aggregate amount of tradable pollution permits and in which market forces, coupled with decentralized tax/subsidy policies, determine the spatial distribution of these permits and the associated pollution. Specifically, let $\bar{k}$ now denote the aggregate amount of pollution to be permitted by the central authority, and let $k_{i}$ denote the amount of pollution permits acquired by firms in jurisdiction $i$. The amount of output in locality $i$ is naturally assumed to be an increasing and concave function $f_{i}\left(k_{i}\right)$ of the amount of permits (and pollution) there; tradable permits in effect transform pollution into another marketed input in the production process. Assume that the national authority distributes the proceeds from the sale of permits in a lump-sum fashion to the households in the economy. This is equivalent to endowing the residents of each jurisdiction with ownership rights to some amount $\bar{k}_{i}$ of pollution permits. (The variables $\bar{k}, k_{i}$, etc. may be interpreted as vectors, thus covering the case where there are many types of pollutants and pollution permits.)

Provided that individual jurisdictions are free to tax or subsidize the local use of pollution permits, corresponding to $k^{i}$ in our model, Proposition 1 (or its generalization to the many-mobile-resource case) implies that the equilibrium distribution of pollution among jurisdictions will be Pareto efficient. In other words, in order to achieve an efficient allocation of resources, the national government need only determine the proper aggregate amount of pollution $\bar{k}$, leaving it to local jurisdictions to attract or repel polluting activities to whatever degree best serves local interests. Local governments, in this case, use local information to promote local interests, and in doing so they insure that the aggregate amount of pollution, determined at the national level, is distributed efficiently among localities. This is true even when environmental effects spill over from one jurisdiction to another.

Pareto-Irrelevant Externalities. Our model demonstrates that if a unit of capital discharges an equivalent amount of pollution in all regions, the externalities are completely internalized through decentralized decision-making. Pareto-irrelevant externalities are also found in some 
previous research in which specific preference structures are utilized. As discussed in Myles (1995), Osana (1972) shows that individual decision-making leads to efficient equilibria in an interpersonal consumption externality framework if the utility function is given by $u^{h}=$ $x_{1}^{h} x_{2}^{h}\left(x_{1}^{j} x_{2}^{j}\right)^{\rho^{h}}$, where $x_{i}^{k}$ represents the consumption of good $i(=1,2)$ 's by individual $k(=$ $h, j)$. The term $\left(x_{1}^{j} x_{2}^{j}\right)^{\rho^{h}}$ captures the externality effects on individual $h$ from individual $j$ 's consumption. Parks (1991) shows that these results generalize to the case where the utility function has the form $u^{h}=u^{h}\left[f^{1}\left(x^{1}\right), f^{2}\left(x^{2}\right), \ldots, f^{H}\left(x^{H}\right)\right]$, where $f^{k}(k=1,2, \ldots, H)$ is the "private utility" that individual $k$ obtains from own-consumption. Of course, these results do impose quite specific restrictions on preferences.

In our present model, the condition we need to achieve Pareto efficiency in decentralized policy making is that one unit of capital discharges an equivalent amount of pollution in all regions. Whether this condition holds or not is a matter of environmental technology. In certain pollution cases, this condition might always hold in the chemical change (formula). Furthermore, we might say that environmental technical transfer among countries is relevant in the tax competing economy not only to improve environmental quality but also to solve externality problems. Developed countries devised new techniques to control pollution associated with rapid economic growth in the 1960-70s. Now these countries transfer environment technology to the various developing countries. Their intent was merely to reduce environmental pollution in those countries. However, we find from our results that it has side (but more important) effects; it also improves the environment technological gap among the countries, and that contributes to lead the decentralized equilibrium to Pareto efficiency.

\section{Conclusion}

The problem of spillover externalities is one that arises in many contexts. Environmental pollution is one important example. It is natural to expect that spillovers, whether positive or negative, may result in inefficient resource allocation unless they are effectively internalized 
through Coasian contracting or by corrective policies by a higher-level government. Indeed, this possibility has long been known in the specific context of local public economics at least since Williams (1966), which is just an application of a standard consumption-externality framework to the issue of interjurisdictional spillovers, and it is emphasized throughout the literature on "environmental federalism" (see, e.g., Oates (2002) for discussion and references). The literature on global climate change, as exemplied by the recent Stern (2007) report, highlights the importance of global environmental externalities and the need for explicit international cooperation to internalize them.

The preceding analysis has shown, however, that there are important cases in which decentralized policymaking can result in efficient allocations of resources for an economic system. We analyze a class of models in which there are interjurisdictional spillovers among heterogeneous jurisdictions and in which it nevertheless is the case that decentralized policymaking leads to efficient resource allocations - even in the complete absence of corrective interventions by higher-level governments or coordination of policy through Coasian bargaining. A critical feature of these models is that jurisdictions interact not only through pollution or other spillovers, but through an integrated and competitive market for capital (in our baseline model) or for some other resource linked to the production of spillover effects, and that governments are free to tax (or subsidize) this competitively-traded resource. Decentralized taxation of freely-mobile capital or other resources is often seen as a source of interjurisdictional fiscal externalities that give rise to allocative inefficiency (for discussion and references, see, e.g., Wilson (1999) or Wilson and Wildasin (2004)). By contrast, in the present analysis, competition for mobile resources plays a crucial role in providing efficiency-enhancing interjurisdictional linkages. Decentralized taxation is essential here; if governments were to rely solely on other revenue sources, the competition allocation of capital would result in equalization of capital productivity in all locations, an allocation that is generally inefficient when economic activity generates environmental or other externalities in a system of heterogeneous jurisdictions. 
We do not wish to claim, and our analysis does not show, that decentralized policymaking invariably leads to efficient resource allocation. In particular, although our model is very general in important respects, it must be noted that the efficiency results derived here do rely on several simplifying assumptions. The results are not knife-edge results that disappear with small departures from the underlying assumptions, but it is nonetheless true that the results are unlikely to be of use in situations in which the key assumptions are only poorly approximated.

\section{References}

Blomstrom M and A Kokko (1998), Multinational corporations and spillovers, Journal of Economic Systems 12, 247-277.

Boadway R, Pestieau P and Wildasin D (1989), Non-Cooperative Behavior and Efficient Provision of Public Goods. Public Finance/Finances Publiques 44: 1-7.

Clarke EH (1971), Multipart pricing of public goods, Public Choice 11, 17-33.

Coase RH (1960), The problem of social cost, Journal of Law and Economics 3, 1-44.

Cremer H and F Gahvari (2004), Environmental taxation, tax competition, and harmonization, Journal of Urban economics 55, 21-45.

Fischel, W (2001), The Homevoter Hypothesis: How Home Values Influence Local Government Taxation, School Finance, and Land-Use Policies. Cambridge: Harvard University Press.

Fudenberg D and E Maskin (1986), The folk theorem for repeated games with discounting and incomplete information, Econometrica 54, 533-554.

Glazer A (1999), Local regulation may be excessively stringent, Regional Science and Urban Economics 29, 553-558. 
Groves T and J Ledyard (1977), Optimal allocation of public goods: a solution to the "free rider" problem, Econometrica 45, 783-809.

Hamilton BW (1975), Zoning and property taxation in a system of local governments, Urban Studies 12, 205-211.

Kunce M and JF Shogren (2002), On environmental federalism and direct emission control, Journal of Urban Economics 51, 238-245.

Myles GD (1995), Public Economics, New York: Cambridge University Press.

Oates, WE (2002), A Reconsideration of Environmental Federalism, in JA List and A de Zeeuw (eds.), Recent Advances in Environmental Economics, Edward Elgar, Cheltenham.

Oates WE and RM Schwab (1988), Economic competition among jurisdictions: Efficiency enhancing or distortion inducing?, Journal of Public Economics 35, 333-354.

Osana H (1972), Externalities and the basic theorem of welfare economics, Journal of Economic Theory 4, 401-414.

Parks RP (1991), Pareto irrelevant externalities, Journal of Economic Theory 54, 165-179.

Pigou AC (1920), The Economics of Welfare, New York: Macmillan.

Stern N (2007) The Economics of Climate Change: The Stern Review, Cambridge: Cambridge University Press.

Stigler GJ (1966), The Theory of Price 3rd ed, New York: Macmillan.

Varian HR (1994), A solution to the problem of externalities when agents are well-informed, American Economic Review 84, 1278-1293.

Wellisch D (1995), Locational choices of firms and decentralized environmental policy with various instruments, Journal of Urban 
Economics 37, 290-310.

Williams A (1966), Optimal Provision of Public Goods in a System of Local Government, Journal of Political Economy 74, 18-33.

Wilson JD (1997), Capital mobility and environmental standards: Is there a theoretical basis for a race to the bottom?, Bhagwati J and EH Robert eds., Fair Trade and Harmonization: Prerequisites for Free Trade? vol. 1, Cambridge: MIT Press.

Wilson JD (1999), Theories of tax competition, National Tax Journal 52, 269-304.

Wilson, JD and DE Wildasin (2004), Capital Tax Competition: Bane or Boon? Journal of Public Economics 88, 1065-1091.

Zodrow RG (2003), Tax competition and tax coordination in the European Union, International Tax and Public Finance 10, 651-671. 


\section{CESifo Working Paper Series}

for full list see www.cesifo-group.org/wp

(address: Poschingerstr. 5, 81679 Munich, Germany, office@cesifo.de)

2080 Christian Bauer, Paul De Grauwe and Stefan Reitz, Exchange Rates Dynamics in a Target Zone - A Heterogeneous Expectations Approach, August 2007

2081 Ana Rute Cardoso, Miguel Portela, Carla Sá and Fernando Alexandre, Demand for Higher Education Programs: The Impact of the Bologna Process, August 2007

2082 Christian Hopp and Axel Dreher, Do Differences in Institutional and Legal Environments Explain Cross-Country Variations in IPO Underpricing?, August 2007

2083 Hans-Werner Sinn, Pareto Optimality in the Extraction of Fossil Fuels and the Greenhouse Effect: A Note, August 2007

2084 Robert Fenge, Maximilian von Ehrlich and Matthias Wrede, Fiscal Competition, Convergence and Agglomeration, August 2007

2085 Volker Nitsch, Die Another Day: Duration in German Import Trade, August 2007

2086 Kam Ki Tang and Jie Zhang, Morbidity, Mortality, Health Expenditures and Annuitization, August 2007

2087 Hans-Werner Sinn, Public Policies against Global Warming, August 2007

2088 Arti Grover, International Outsourcing and the Supply Side Productivity Determinants, September 2007

2089 M. Alejandra Cattaneo and Stefan C. Wolter, Are the Elderly a Threat to Educational Expenditures?, September 2007

2090 Ted Bergstrom, Rod Garratt and Damien Sheehan-Connor, One Chance in a Million: Altruism and the Bone Marrow Registry, September 2007

2091 Geraldo Cerqueiro, Hans Degryse and Steven Ongena, Rules versus Discretion in Loan Rate Setting, September 2007

2092 Henrik Jacobsen Kleven, Claus Thustrup Kreiner and Emmanuel Saez, The Optimal Income Taxation of Couples as a Multi-Dimensional Screening Problem, September 2007

2093 Michael Rauber and Heinrich W. Ursprung, Life Cycle and Cohort Productivity in Economic Research: The Case of Germany, September 2007

2094 David B. Audretsch, Oliver Falck and Stephan Heblich, It’s All in Marshall: The Impact of External Economies on Regional Dynamics, September 2007 
2095 Michael Binder and Christian J. Offermanns, International Investment Positions and Exchange Rate Dynamics: A Dynamic Panel Analysis, September 2007

2096 Louis N. Christofides and Amy Chen Peng, Real Wage Chronologies, September 2007

2097 Martin Kolmar and Andreas Wagener, Tax Competition with Formula Apportionment: The Interaction between Tax Base and Sharing Mechanism, September 2007

2098 Daniela Treutlein, What actually Happens to EU Directives in the Member States? - A Cross-Country Cross-Sector View on National Transposition Instruments, September 2007

2099 Emmanuel C. Mamatzakis, An Analysis of the Impact of Public Infrastructure on Productivity Performance of Mexican Industry, September 2007

2100 Gunther Schnabl and Andreas Hoffmann, Monetary Policy, Vagabonding Liquidity and Bursting Bubbles in New and Emerging Markets - An Overinvestment View, September 2007

2101 Panu Poutvaara, The Expansion of Higher Education and Time-Consistent Taxation, September 2007

2102 Marko Koethenbuerger and Ben Lockwood, Does Tax Competition Really Promote Growth?, September 2007

2103 M. Hashem Pesaran and Elisa Tosetti, Large Panels with Common Factors and Spatial Correlations, September 2007

2104 Laszlo Goerke and Marco Runkel, Tax Evasion and Competition, September 2007

2105 Scott Alan Carson, Slave Prices, Geography and Insolation in $19^{\text {th }}$ Century AfricanAmerican Stature, September 2007

2106 Wolfram F. Richter, Efficient Tax Policy Ranks Education Higher than Saving, October 2007

2107 Jarko Fidrmuc and Roman Horváth, Volatility of Exchange Rates in Selected New EU Members: Evidence from Daily Data, October 2007

2108 Torben M. Andersen and Michael Svarer, Flexicurity - Labour Market Performance in Denmark, October 2007

2109 Jonathan P. Thomas and Tim Worrall, Limited Commitment Models of the Labor Market, October 2007

2110 Carlos Pestana Barros, Guglielmo Maria Caporale and Luis A. Gil-Alana, Identification of Segments of European Banks with a Latent Class Frontier Model, October 2007

2111 Felicitas Nowak-Lehmann D., Sebastian Vollmer and Immaculada Martínez-Zarzoso, Competitiveness - A Comparison of China and Mexico, October 2007 
2112 Mark Mink, Jan P.A.M. Jacobs and Jakob de Haan, Measuring Synchronicity and Comovement of Business Cycles with an Application to the Euro Area, October 2007

2113 Ossip Hühnerbein and Tobias Seidel, Intra-regional Tax Competition and Economic Geography, October 2007

2114 Christian Keuschnigg, Exports, Foreign Direct Investment and the Costs of Corporate Taxation, October 2007

2115 Werner Bönte, Oliver Falck and Stephan Heblich, Demography and Innovative Entrepreneurship, October 2007

2116 Katrin Assenmacher-Wesche and M. Hashem Pesaran, Assessing Forecast Uncertainties in a VECX Model for Switzerland: An Exercise in Forecast Combination across Models and Observation Windows, October 2007

2117 Ben Lockwood, Voting, Lobbying, and the Decentralization Theorem, October 2007

2118 Andrea Ichino, Guido Schwerdt, Rudolf Winter-Ebmer and Josef Zweimüller, Too Old to Work, too Young to Retire?, October 2007

2119 Wolfgang Eggert, Tim Krieger and Volker Meier, Education, Unemployment and Migration, October 2007

2120 Stefan Napel and Mika Widgrén, The European Commission - Appointment, Preferences, and Institutional Relations, October 2007

2121 Bertil Holmlund and Martin Söderström, Estimating Income Responses to Tax Changes: A Dynamic Panel Data Approach, October 2007

2122 Doina Maria Radulescu, From Separate Accounting to Formula Apportionment: Analysis in a Dynamic Framework, October 2007

2123 Jelle Brouwer, Richard Paap and Jean-Marie Viaene, The Trade and FDI Effects of EMU Enlargement, October 2007

2124 Kurt R. Brekke, Luigi Siciliani and Odd Rune Straume, Competition and Waiting Times in Hospital Markets, October 2007

2125 Alexis Direr, Flexible Life Annuities, October 2007

2126 Johannes Becker and Clemens Fuest, Quality versus Quantity - The Composition Effect of Corporate Taxation on Foreign Direct Investment, October 2007

2127 Balázs Égert, Real Convergence, Price Level Convergence and Inflation Differentials in Europe, October 2007

2128 Marko Koethenbuerger, Revisiting the "Decentralization Theorem" - On the Role of Externalities, October 2007 
2129 Axel Dreher, Silvia Marchesi and James Raymond Vreeland, The Politics of IMF Forecasts, October 2007

2130 Andreas Knabe and Ronnie Schöb, Subsidizing Extra Jobs: Promoting Employment by Taming the Unions, October 2007

2131 Michel Beine and Bertrand Candelon, Liberalization and Stock Market Co-Movement between Emerging Economies, October 2007

2132 Dieter M. Urban, FDI Technology Spillovers and Wages, October 2007

2133 Valentina Bosetti, Carlo Carraro, Emanuele Massetti and Massimo Tavoni, Optimal Energy Investment and R\&D Strategies to Stabilise Greenhouse Gas Atmospheric Concentrations, October 2007

2134 David-Jan Jansen and Jakob de Haan, The Importance of Being Vigilant: Has ECB Communication Influenced Euro Area Inflation Expectations?, October 2007

2135 Oliver Falck, Heavyweights - The Impact of Large Businesses on Productivity Growth, October 2007

2136 Xavier Freixas and Bruno M. Parigi, Banking Regulation and Prompt Corrective Action, November 2007

2137 Jan K. Brueckner, Partial Fiscal Decentralization, November 2007

2138 Silvia Console Battilana, Uncovered Power: External Agenda Setting, Sophisticated Voting, and Transnational Lobbying, November 2007

2139 Alan J. Auerbach, Michael P. Devereux and Helen Simpson, Taxing Corporate Income, November 2007

2140 Lorenzo Cappellari, Paolo Ghinetti and Gilberto Turati, On Time and Money Donations, November 2007

2141 Roel Beetsma and Heikki Oksanen, Pension Systems, Ageing and the Stability and Growth Pact, November 2007

2142 Hikaru Ogawa and David E. Wildasin, Think Locally, Act Locally: Spillovers, Spillbacks, and Efficient Decentralized Policymaking, November 2007 